\title{
Relating Land Use and Transport Modeling with Transportation Asset Management
}

\author{
Luis Esteban Amador-Jiménez ${ }^{1}$ \\ ${ }^{1} \mathrm{PhD}$, Assistant Professor, Dept. of Building, Civil and Environmental Engineering, \\ Concordia University, Montreal, PQ, Canada, H3G 1M8. Email: \\ amador@.encs.concordia.ca
}

\section{ABSTRACT}

Increasing computing capacity has made possible the use of advanced simulation and optimization methods to solve complex problems in transportation and urban planning. Methods such as linear programming and heuristic optimization have made it possible to find the most cost-effective solution for allocating resources among competing alternatives. Agent based approaches and regional econometric models have succeeded to simulate urban development, economic growth and their impacts across modes of transportation. This paper examines the advantages of incorporating Land Use and Transport Modeling into Asset Management and presents a framework for accomplishing such an objective; especially for timing maintenance, rehabilitation and capital projects to improve safety, mobility and condition. It suggests that decisions for scheduling rehabilitation of existing links and construction of new projects should be based on user impacts and expected gains in terms of regional economic benefits.

CE Database subject headings: transportation asset management; integrated land use and transportation; decision making analytical tools, capital projects; mobility; safety; condition.

\section{Introduction}

Even though literature on pavement management can be traced back to the 1960s (Haas and Hudson 1994), it was not until the 1990s that pavement management systems started to be adopted in developed countries (TAC 1997). Transportation asset management (TAM) seems to have evolved from pavement management systems. Earliest developments of transportation asset management date back to the 1970s with progressive legislation found in the Local Governments Act of New Zealand. In 1995 the National Asset Management Steering Group from New Zealand became one of the first organizations to formally adopt such methods for the management of civil infrastructure (NAMS 2006). A few years later, the Federal Highway Administration (1999) followed a similar path identifying transportation asset management as the decision making process to achieve long-term sustainability of transportation assets. The FHWA (1999) along with the NAMS (2006), recognized that modern civil infrastructure's asset management is an approach that 
incorporates the economic assessment of trade-offs between competing alternatives, and that information is the critical factor to make cost-effective decisions (Ouertany et al. 2008).

However, to date practical implementations of Transportation Asset Management (TAM) have faced several limitations (NCHRP 2005): (1) Static performance modeling that fails to recognize the dynamic nature of a changing network of assets (i.e., condition, safety and capacity) that in reality respond to changes on the demand, which in turn represents the evolution of urban patterns and establishment of new industries and economic development. (2) Analytical tools with limited capability for incorporating multiple objectives across modes of transportation. (3) Other practicalities related to the need of a modeling mechanism capable of capturing treatment effectiveness from historical observations.

According to Batty (1979), initial developments on integrated Land Use and Transportation (LUT) date back from the 1950s. However, it wasn't until the 1960s with Lowry (1964) that the first operational model, based on spatial interaction and gravity theory, appears (Iacono et al. 2008). During the 1980's a second generation of models based on random utility (i.e., multinomial and nested logit) exhibited better representation of urban dynamics incorporating more detailed modeling of spatial economics and land market changes. More disaggregated models (i.e., agent or cell based) appeared during the 1990s modeling urban dynamics from a bottom up approach. Since then, advances on LUT modeling have attempted to refine the simulation in order to reproduce urban development and its impacts on the transportation network (Hunt et al. 2005).

\section{Paper Objective}

To propose an improved decision making framework capable of supporting a more comprehensive Transportation Asset Management by incorporating simulation capabilities from Land Use and Transport modeling into Asset Management.

\section{Review of TAM and LUT models}

\section{Transportation Asset Management}

Recent advances on TAM have focused on improving analytical tools to achieve the most cost-effective solution for maintenance and rehabilitation of civil infrastructure. Today's state of the practice on infrastructure asset management relies on trade-off global optimization for selecting the optimal set of actions among competing alternatives to maintain, rehabilitate and upgrade networks of infrastructure assets (NCHRP 2005). It's well known than applying an adequate treatment at the right time will positively impact the service life of any asset. While some treatments translate into a rejuvenation of the asset, others only slow down the deterioration rate (Figure 2). However, treatment availability depends on asset type; while for pavements there is a wide range of options across different stages of the lifespan (Figure 3); for water 
systems and pipe networks there are very few. In addition, more research is required to formally document the effectiveness and post-treatment performance of any asset.

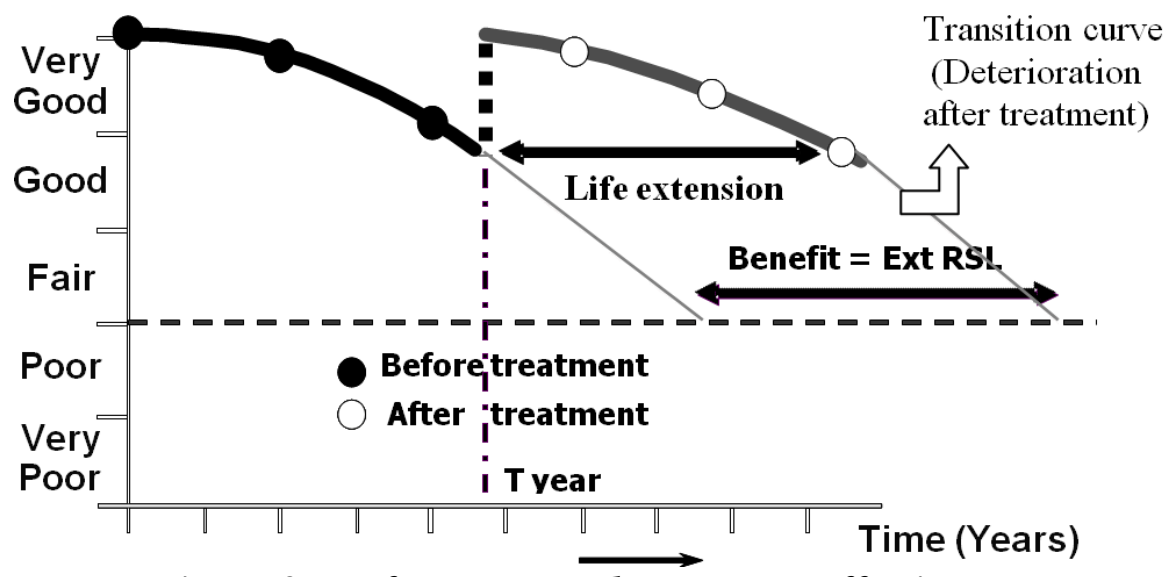

Figure 2. Performance and Treatment effectiveness

Once treatments have been identified, and the objectives selected, a decision making analytical tool chooses among competing alternatives. Historical, advances in decision making tools can be traced back to the 1980s with some state level implementations of pavement management systems. Some tools such as the PAVER and the HDM3 were based on cost-benefit analysis for single periods of time with no consideration on how today's decisions impact the long term achievement of agency's goals. In addition, such models were incapable of trade-off analyses across asset types. Another drawback was the large amount of data required to calibrate these models.

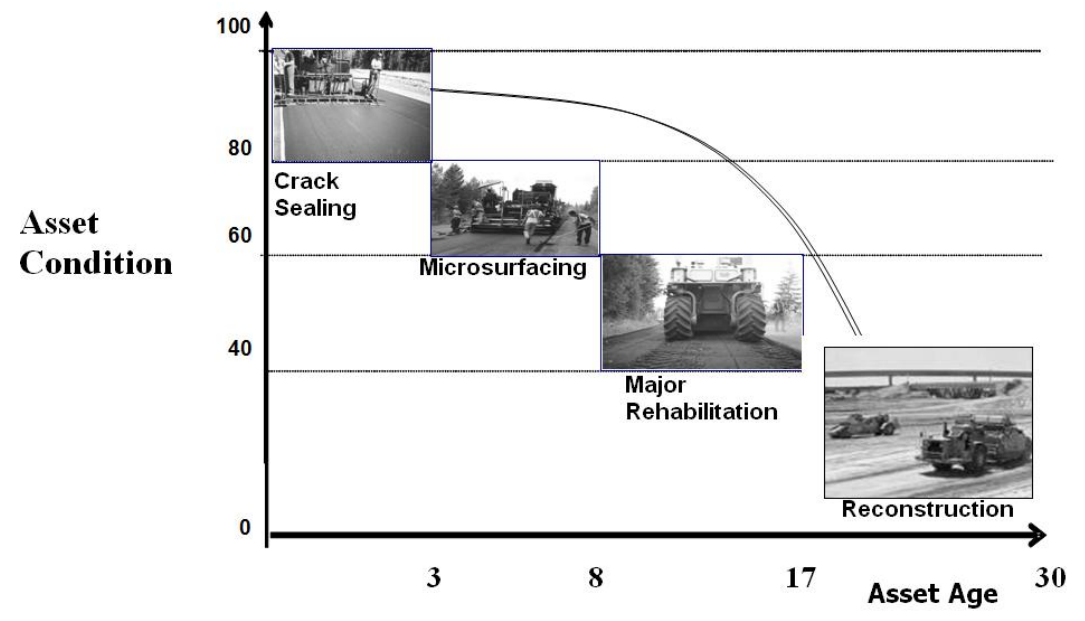

Figure 3. Sample of common treatments for pavements

The adaptation of linear programming and other optimization techniques for asset management addressed most of those issues. Linear optimization was capable of finding the optimal path (Figure 4) to take full advantage of cost-effectiveness of individual treatments (what treatment?), associated with individual asset elements 
(where?), and benefits of advancing or deferring a certain treatment (at what time?). It will seek an allocation that will minimize costs (or maximize the benefits, or any other measures of return on investment) over the whole network of assets in the long run.

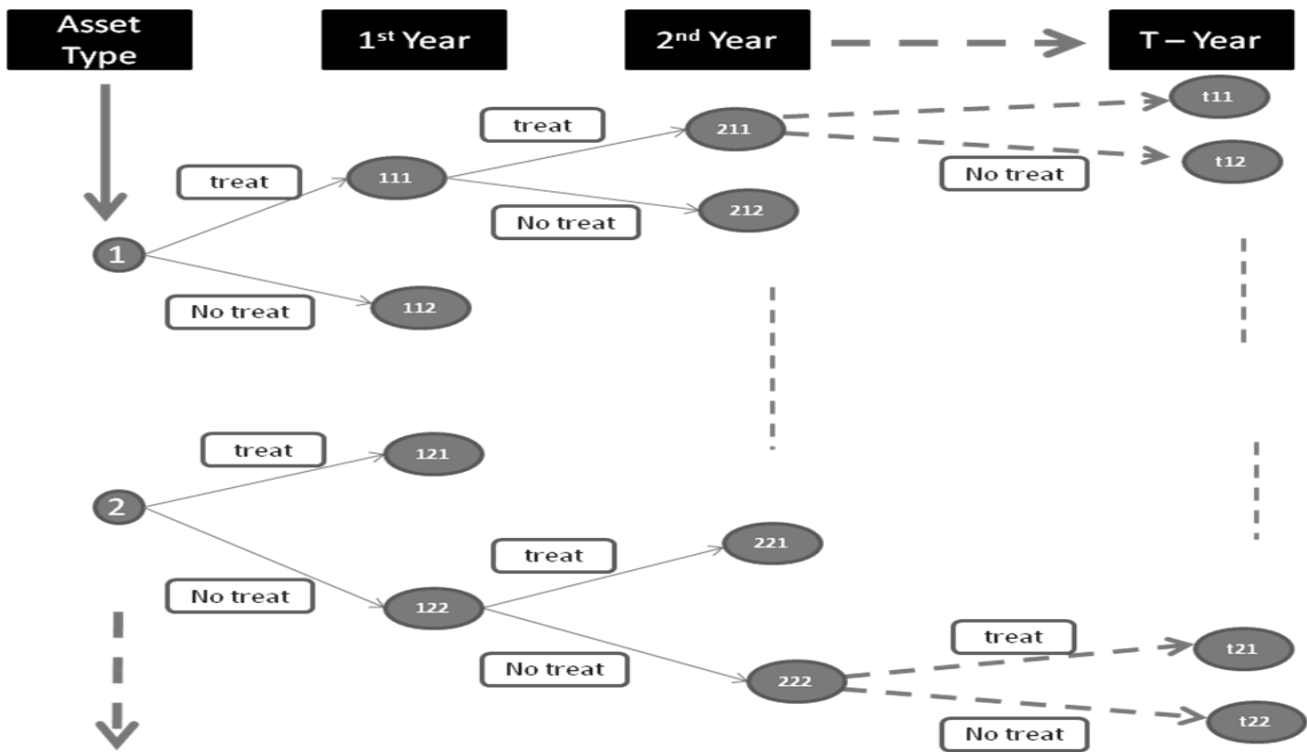

Figure 4. Graphical representation of possible paths

Today's state of the art in civil infrastructure management systems is advancing on two fronts: more reliable performance modeling and improved techniques for decision making capable of allocating actions across different networks of assets, across time and for several objectives. Such decision-making tools can even be expanded to make decisions across different modes of the transportation. Table 1 summarizes historical advances on civil infrastructure management systems.

Table 1. Historical comparison of Infrastructure Management Systems

\begin{tabular}{|c|c|c|c|c|}
\hline Time & Description & $\begin{array}{l}\text { Analytical } \\
\text { Tools }\end{array}$ & $\begin{array}{c}\text { Sample } \\
\text { Analytical tool }\end{array}$ & $\begin{array}{l}\text { Performance } \\
\text { Modeling }\end{array}$ \\
\hline $1980 \mathrm{~s}$ & $\begin{array}{l}\text { Pavements only. Some } \\
\text { with GIS interface }\end{array}$ & $\begin{array}{l}\text { Cost-benefit } \\
\text { analysis }\end{array}$ & $\begin{array}{l}\text { HDM3, HERST, } \\
\text { PAVER }\end{array}$ & Deterministic \\
\hline $1990 \mathrm{~s}$ & $\begin{array}{l}\text { Originally designed for } \\
\text { pavements, extended to } \\
\text { Civil Infrastructure }\end{array}$ & \multirow{2}{*}{$\begin{array}{c}\text { Linear } \\
\text { Programming } \\
\text { Optimization }\end{array}$} & VEMAX & $\begin{array}{l}\text { Stochastic (Semi- } \\
\text { Markov) }\end{array}$ \\
\hline $2000 s$ & $\begin{array}{l}\text { Adapted from Forestry, } \\
\text { Goal /weighted objectives, } \\
\text { custom defined modules. } \\
\text { GIS interface }\end{array}$ & & REMSOFT & Deterministic \\
\hline $2010 s$ & $\begin{array}{l}\text { Across assets, multiple } \\
\text { objectives, across assets, } \\
\text { spatial-temporal } \\
\text { coordination of activities }\end{array}$ & $\begin{array}{l}\text { Heuristic - } \\
\text { Evolutionary } \\
\text { Algorithms }\end{array}$ & $\begin{array}{c}\text { Under } \\
\text { Development }\end{array}$ & $\begin{array}{l}\text { Mechanistic-with } \\
\text { some empirical, } \\
\text { Stochastic } \\
\text { (MCMC- } \\
\text { Bayesian), } \\
\text { Nested }\end{array}$ \\
\hline
\end{tabular}




\section{Land Use and Transportation modeling}

Land use and transportation models strive to capture processes of change on land development due to economic interactions \& development in order to forecast levels of demand across modes of the transportation network. Two main approaches have been historically employed to simulate spatial dynamics and transport modeling: (1) Regional economic models and, (2) Micro simulation models. Although both pursue the same objective, their approach departs from opposite ends. On one hand, regional economic models base their simulation on a top-down approach in which macro aggregated trade zones are used to predict flows of commodities, which are then converted into demand for commercial and passenger traffic. Congestion from the transport network feed back into the original trade system by increasing a disutility function which penalizes modal links.

On the other hand, micro simulation models use a bottom up approach, which departs from disaggregated agents and small economic units to reach a macro-level of interactions in which trade flows between economic activities and levels of demand for the transportation network are determined. Other forms based on cellular automata and complexity theory return to the original aims of spatial interaction models attempting to capture the spatial dynamics of a region disregarding close form econometric relationships. Table 2 summarizes advances on Land Use and Transport modeling.

Table 2. Advances on Land Use \&Transport models

\begin{tabular}{|c|c|c|c|c|}
\hline Generation & Description & Theory & Model & Complexity \\
\hline $1^{\mathrm{st}}-1960 \mathrm{~s}$ & $\begin{array}{c}\text { Spatial } \\
\text { Interactions }\end{array}$ & Gravity-based & ITLUP, IRUPD & $\begin{array}{l}\text { Low; employ } \\
\text { coefficients for } \\
\text { attractiveness }\end{array}$ \\
\hline \multirow[t]{2}{*}{$2^{\text {nd }}-1980 \mathrm{~s}$} & $\begin{array}{c}\text { Regional } \\
\text { Economics }\end{array}$ & \multirow{2}{*}{$\begin{array}{l}\text { Random Utility } \\
\text { Multinomial Logit / } \\
\text { Nested Logit }\end{array}$} & $\begin{array}{l}\text { TRANUS, } \\
\text { MEPLAN }\end{array}$ & \multirow{2}{*}{$\begin{array}{c}\text { Medium; required } \\
\text { aggregated census } \\
\text { data at zone level } \\
\text { per industry }\end{array}$} \\
\hline & $\begin{array}{c}\text { Land } \\
\text { Market }\end{array}$ & & $\begin{array}{l}\text { METROSIM, } \\
\text { MUSSSA }\end{array}$ & \\
\hline $3^{\text {rd }}-1990 \mathrm{~s}$ & $\begin{array}{l}\text { Agent-cell } \\
\text { Based }\end{array}$ & $\begin{array}{l}\text { Micro-simulation, } \\
\text { Cellular Automata }\end{array}$ & $\begin{array}{c}\text { PECAS, ILUTE } \\
\text { Urban Sim, } \\
\text { MALUT, } \\
\text { LUCI2 }\end{array}$ & $\begin{array}{c}\text { Required detailed } \\
\text { disaggregated } \\
\text { information from } \\
\text { census data }\end{array}$ \\
\hline
\end{tabular}

While more accurate for metropolitan (city) wide level, micro simulation models suffer from drawbacks related to calibration for which they are data hungry. Rather, regional economic models are less complex systems that perform well on a regional basis. This paper recommends the use of regional econometric models for state/province wide implementations and micro-simulation based approaches for city level (metropolitan region) urban systems that are by nature dynamic and complex (Batty 2005, Iacono et al. 2008).

The key steps of Land Use and Transport modeling are presented on Figure 5; following a regional economics approach, an initial calibration is performed in order 
to fit observed data by estimating a set of factors, checking model agreement with production and land prices by sectors. Then, future location of activities is predicted along with floorspace and land values estimates (de la Barra 2005). Secondly, trade flows are estimated and converted into demand for commercial and passenger traffic. Such demands are allocated across transportation modes to a set of paths or travel options. Demands load different modes of the network, which in turn translate into increased travel time and other disutilities that affect the location of activities. A model based on micro-simulation undertakes a bottom up approach (Iacono et al. 2008) in which the urban dynamics are disaggregated into agents and units, therefore the model is initially calibrated to fit observations at that level and other macro activities are generated by aggregating activities to regions (zones) and industries. The rest of the process goes in similar fashion as the abovementioned.

\section{A framework for improved decision making on TAM}

As aforementioned, one of the key features of any Land Use and Transport models is its capability to update the model parameters based on travel disutilities associated to particular links and network modes. Travel time is currently the most employed function to capture disutility (Iacono et al. 2008, Hunt el al. 2005, De la Barra 2005). The first variant proposed by this paper is to modify the disutilities function to incorporate measures of mobility, condition and safety. As shown on Figure 5, mobility translates not only to travel time but also to vehicle operating cost because it accounts for the level of service on any link (i.e., congestion), fuel consumption and vehicle deterioration.

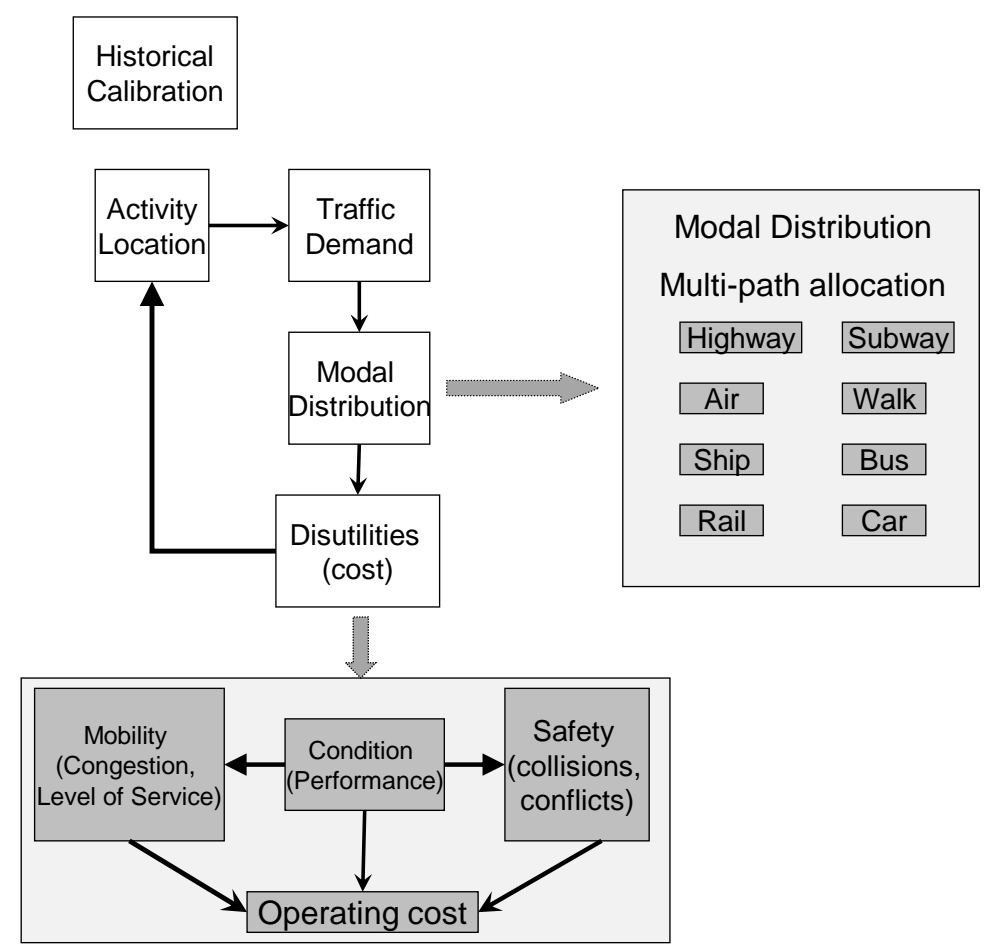

Figure 5. Conceptual LUT Regional Economic Model 
However, existing LUT models do not incorporate safety and its impacts on travel behavior. There is sufficient research to prove that drivers perception of road safety is a factor in the choice of routes and links for passenger cars (Hildebrand 2003). Another argument can go towards increased travel time as a function of the number of conflicting points (TAC 1999). Finally, drivers in general would tend to choose those roads with better surface condition (i.e., low roughness). Lower levels of condition negatively impact safety and mobility; drivers would be discouraged to drive at maximum operational speed if the ride is rough, which translates on increased travel time. Drivers would tend to avoid damage on the road surface (i.e., potholes, settlements, etc), which may turn into unexpected behavior compromising road safety. In summary all three factors would likely impact travel time, vehicle operating cost and insurance premiums, which in turn translate into additional production cost. This in general goes in detriment of the overall productivity of any industry.

This paper proposes to measure and incorporate the performance on the three factors as part of an improved TAM system (Figure 6). For the same reason projects that have been identified as candidates to improve any of these aspects (i.e., mobility, condition and safety) will be incorporated in the pool of assets, carrying a special index to recognize the fact that they are still not part of the network (Figure 6). The decision making tool will treat them as belonging to a new dimension when generating the full combinatorial space of treatments across time in order to select the optimal path as explained in Figure 4.

The other key element for incorporating LUT into TAM is their capability to measure the economic impact of any new project and the overall impact in the network (Figure 5).

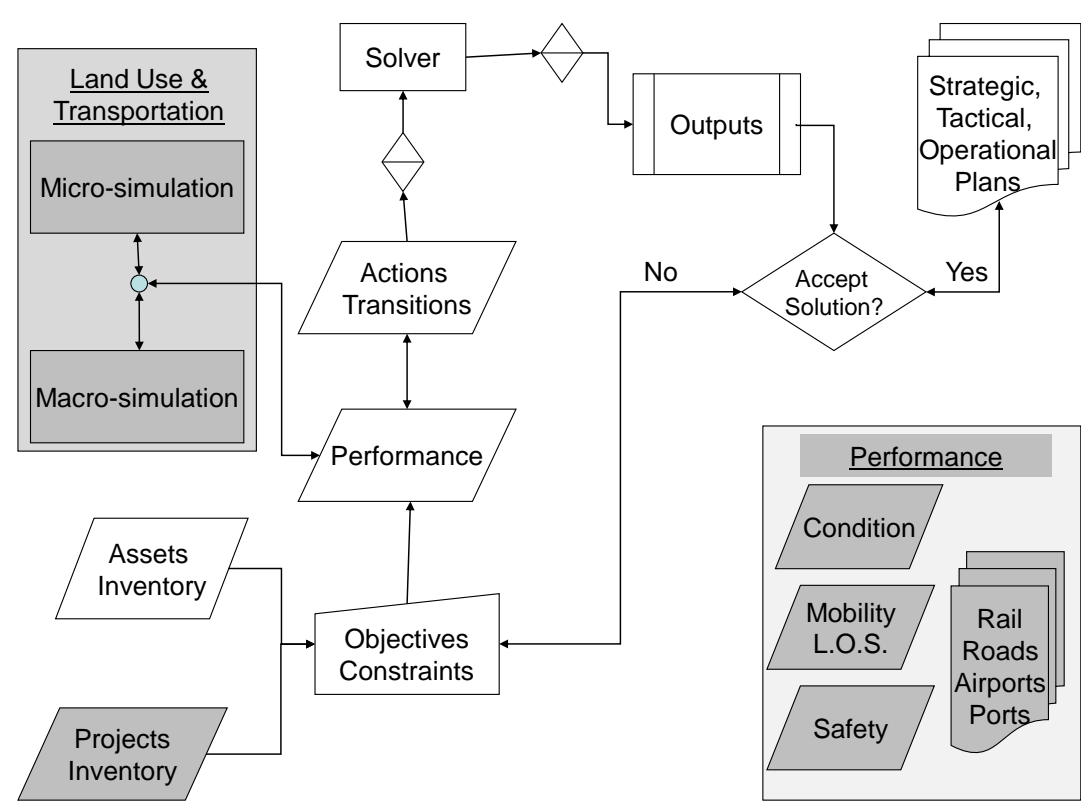

Figure 6. Improved TAM system which incorporates LUT modeling capabilities 
This key feature will allow planners to improve their decision making by realizing of the cost effectiveness of incorporating new links in the network and how far the benefits of such capital projects will go. Another important consideration is that of redistribution of the demand across links of the network after the construction of a new project and how that affects condition, safety and mobility. Therefore, the individual contribution of any project will be assessed within the decision making analytical tool in terms of economic contribution and improvement in safety, condition and mobility, which are typical objectives on any Asset Management system (Figure 6). Such elements would be incorporated and updated on the Performance model subcomponent of the TAM.

\section{Conclusions}

The integration of LUT modeling capabilities within a TAM system will support a more comprehensive multimodal decision making framework in which decisions are allocated among competing alternatives for improving safety, condition and mobility in order to maximize the cost-effectiveness of the transportation network and the economic benefits (i.e., productivity) of local industries.

\section{References}

Batty, M. (1979). "Progress, success and failure in urban modeling". Environment and Planning A, volume 11(8), pp 863-878.

Batty, M. (2005). "Cities and Complexity: Understanding Cities with Cellular Automata, Agent-based models and Fractals". MIT Press Cambridge, Massachusetts.

Batty, M. (2008). "Cities as Complex Systems: Scaling, Interactions, Networks, Dynamics and Urban Morphologies". Centre for Advanced Spatial Analysis University College London, Paper 131, London, U.K.

De la Barra, T. (2005). "Integrated land use and transport modeling: decision chains and hierarchies". Cambridge Urban and Architectural Studies. $1^{\text {st }}$ paperback version. Cambridge University Press, New York, NY.

FHWA. (1999). “Asset Management Primer”. Office of Asset Management, Federal Highway Administration, Washington, DC., USA.

Haas, R., Hudson, W.R., Zaniewski, J. (1994). "Modern Pavement Management". Krieger Publishing Company. Malabar, Florida.

Hildebrand, E. (2003). "Dimensions in elderly travel behaviour: A simplified activity-based model using lifestyle clusters". Journal of Transportation, Springer Netherlands, pp 285 306.

Hunt, J.,D., Kriger, D.,S., and Miller, E.,J. (2005). "Current Operational Land-use- Transport modeling Frameworks: A Review”. Transport Reviews. Volume 25. No-3. pp 329-376. 
Iacono, M., Levinson, D., and El-Geneidy, A. (2008). "Models of Transportation and Land Use Change: A Guide to the Territory". Journal of Planning Literature, number 22, pp 323340 .

Lowry, I. S. (1964). A model of Metropolis. Memorandum RM-4035-RC. Rand Corporation. Santa Monica, CA.

NAMS. (2006). "International Infrastructure Management Manual”. National Asset Management Steering Group. New Zealand.

NCHRP. (2005). “Analytical tools for Asset Management". Transportation Research Board. National Cooperative Research Program. Report 545. Washington D.C.

Ouertani, M.Z., Parlikad, A.K., and Mcfarlane, D. (2008). "Towards an approach to select an asset information management strategy". International Journal of Computer Science and Applications. Volume 5, number 3b. pp25 - 44.

TAC. (1997). "Pavement Design and Management Guide", Transportation Association of Canada, National Project Team, Ottawa.

TAC. (1999). Geometric Design Guide for Canadian Roads. Transportation Association of Canada. Ottawa. 